\title{
Integrating Sustainability into Major Infrastructure Projects: Four Perspectives on Sustainable Tunnel Development
}

\author{
Darinde Gijzel, Marian Bosch-Rekveldt *(D), Daan Schraven and Marcel Hertogh \\ Faculty of Civil Engineering and Geosciences, Delft University of Technology, Stevinweg 1, \\ 2628 CN Delft, The Netherlands; daarindezee@gmail.com (D.G.); D.F.J.Schraven@tudelft.nl (D.S.); \\ M.J.C.M.Hertogh@tudelft.nl (M.H.) \\ * Correspondence: m.g.c.bosch-rekveldt@tudelft.nl
}

Received: 28 November 2019; Accepted: 17 December 2019; Published: 18 December 2019

check for updates

\begin{abstract}
Although sustainability is on the agenda of many countries and agencies, it is still a great challenge to properly integrate sustainability into major infrastructure projects, like tunnels. This is remarkable, as it is commonly accepted that the construction and operation of these civil infrastructures have a heavy impact on environmental, economic and social sustainability. In academia, the foregone conclusion seems to point to a lack of vision about sustainability with respect to tunnels. This article presents an empirical study that investigates sustainability ideas amongst tunnel practitioners in the Netherlands. The case was used as a practical environment to get access to tunnel practitioners, to explicitly define the meaning of a sustainable tunnel in its development phase. Perceptions of sustainable tunnels were extracted by means of a commonly accepted research methodology called Q-methodology. By applying this method, four perspectives were obtained: perspectives with a focus on energy, resilience, social or a transitional focus. Each perspective highlights distinct focal points on how to operationalize sustainability for tunnel projects. Each perspective is also accompanied by an anti-focus; how sustainability should not be approached, sometimes contrary to other perspectives. These insights help project practitioners in creating awareness for the existence of different perspectives, and subsequently help to focus project management efforts to implement sustainability in specific projects.
\end{abstract}

Keywords: sustainable project management; sustainable tunnel; perspectives on sustainability; Q-methodology

\section{Introduction}

Sustainability is on the agenda of every industry and is increasingly recognized as an important part of construction projects since this industry not only contributes significantly to environmental pollution but also uses $40 \%$ of the global use of materials and resources [1]. For project managers it is still a challenge, however, to practically integrate sustainability into their construction projects [2-4]. Neither research extensively describes how sustainability could be integrated into project management [5], although single case results are reported showing how project control supports sustainable project management [6].

For a long time, the focus within sustainable construction has been on buildings and there was far less attention for infrastructure and civil works [7-9]. Especially the tunnel industry, as a specific type of civil infrastructure, has been slow in adopting this challenge, as there are not many known examples of sustainable tunnel projects [10]. This puts the adoption of sustainability with respect to tunnel projects into an exploratory character. Tunnels are an interesting focus, because these objects 
are not only complex and expensive, but normally have a long lifespan (up to over 100 years), so an initial investment into sustainability will have a long-lasting effect [11]. Furthermore, these structures have a major impact on the natural environment, are energy-intensive [12] and require a large number of natural resources to construct. Cement is the major component for tunnel construction and this material alone contributes $8 \%$ to all $\mathrm{CO}_{2}$ emissions in the world [13].

As projects are the instruments for change $[5,14,15]$, project management plays a crucial role in implementing sustainability [16]. The start of any project, therefore, provides the opportunity to translate overarching agendas on sustainability into practice [17]. This requires a method to move sustainability from a conceptual level toward tangible interpretations. Thus the question arises, what kind of perspectives on sustainability may exist in tunnel projects and how can these help to integrate sustainability into the project?

This paper addresses this question by means of an in-depth study with practitioners with relevant experience and recent involvement in the integration of sustainability in tunnel projects. Practitioners were purposively sampled for their experience and involvement in a Dutch sustainable tunnel project in its developmental stages. The project was used as a unique access point to cohesively sample the required practitioners for this study through its supply chain. Specifically, the inquiry seeks to elicit perceptions of a sustainable tunnel. A useful and commonly accepted approach for this is called Q-methodology. The Q-methodology is a methodology that can help to identify these hidden perspectives from tunnel construction practitioners about what entails a sustainable tunnel. Understanding these perspectives guides the inclusion of sustainability in project management. Q-methodology is a suitable methodology for this research because it enables us to study subjectivity towards a topic in a systematic way [18]. It was developed in the field of social sciences and is most commonly applied in psychology [19], but it could also successfully be applied to identify how individuals see environmental issues. The Q-methodology assumes that the diversity in views towards a topic is limited [18,19]. This methodology is suitable to elicit a limited amount of dominant perspectives towards a certain topic among the participants [20].

This paper is structured as follows. First, background information on sustainability in the construction, and more specifically, the tunnel industry, is sketched. Next, the empirical data gathering by means of Q-methodology is described. In Section 4 the results are presented, followed by the discussion in Section 5. This paper concludes in Section 6, also providing suggestions for further research.

\section{Background}

Sustainability has been particularly linked to project management through sustainability assessments. Sustainability assessment frameworks and tools have emerged to make sustainability in a project more explicit and to assess the level of sustainability in a project. For assessing sustainability in projects generically, various methods and tools have been proposed [21], ranging from checklists [22], to maturity models [23] and proposed standards [24,25] to impact assessments [26]. This rich list of approaches appears to assess sustainability with different pre-determined compilations of underlying sustainability aspects and with different operationalizations thereof.

The emergence of these sustainability assessment tools highlights the need for the translation of high-level concepts and goals into useable frameworks [27]. Progress in the consideration of sustainability in civil infrastructures, however, has been slow [28]. This could be because sustainability is often intuitively understood, but it appears hard to translate this vague concept into concrete terms $[29,30]$.

The first environmental assessment tools in this sector have been developed for buildings. The first one was published in 1990: The Building Research Establishment Environmental Assessment Method (BREEAM) in the United Kingdom [31]. Nowadays, BREEAM and LEED are the major assessment systems in the built environment [31]. Since 2003, also for infrastructure and civil work, assessment tools have been developed such as the Civil Engineering Environmental Quality (CEEQUAL) and 
BREEAM Infrastructure in the UK, Envision and Greenroads in the US and Infrastructure Sustainability (IS) in Australia [27].

According to Griffiths et al. [27], the right use of rating tools can support infrastructure owners and construction practitioners in making more informed decisions on how to use such tools and in developing their sustainability goals and visions. They reviewed the existing tools, showing among others which life cycle phases are covered by the tools. Only one of the tools (i.e., Envision) is applicable in the planning phase. This is remarkable since this is the moment in a project to integrate sustainability. Although some tunnel projects (for example the Thames Water Ring Main) have been assessed with schemes such as the CEEQUAL for infrastructure [10], no such applications have really offered a tangible way forward.

As infrastructure plays a significant role in sustainable (urban) development, it is striking that sustainability assessments have been less well developed for infrastructures. In fact, civil infrastructure like roads, railways, bridges and tunnels are known to have a great influence on the $\mathrm{CO}_{2}$ emissions of a country. In the United Kingdom, the infrastructure industry is responsible for $16 \%$ of the country's total carbon emissions and indirectly influences an additional $37 \%$, thereby having an impactful role on over $50 \%$ in total [32]. In addition, the infrastructure industry is also a resource-intensive industry. An infrastructure project has a major impact on the direct (living and natural) environment, thereby causing a noise nuisance, air pollution and construction waste. These issues show that the infrastructure sector cannot be neglected in any serious attempt to effectively reduce $\mathrm{CO}_{2}$ emissions or adopt the overall goal of becoming more sustainable.

With regard to sustainability, tunnel projects have a more profound impact than other civil infrastructures. For example, the negative impact on the environment of tunnel construction is larger than the impact of a normal road [33]. The construction process of these structures demands a great amount of material such as cement and steel, including energy-intensive processes with a major impact on the site's environment and community [34]. According to PIARC [11], there are only a few guidelines and best practices available that address the sustainability of road tunnels. This suggests a lack of top-down guidance on integrating sustainability in (the management of) tunnel projects.

The lack of top-down guidance is imperative since there are numerous sustainable developments proposed and experimented from bottom up to improve particular aspects of sustainability for tunnels. For example, various technical solutions have been proposed like green or sustainable lighting [35-37], sustainable tunnel ventilation [38] and green tunnel lining [39]. Even very detailed proposals are made like the forestation of the portal surrounding [40] to decrease the energy demands of lighting. Also, managerial solutions have been proposed. For example, methodologies and tools have been developed to assess the environmental impacts of a tunnel [33,41] Particular, for geotechnical intensive infrastructures, like tunnels, work has also been developed on managing excavated material [39,42]. Finally, life cycle cost analysis has also been conducted on tunnels [43], which could be regarded as a financial life cycle assessment.

These bottom-up technical and managerial solutions illustrate that although all sustainability aspects need to be targeted, progress on single aspects is needed as well. Tarada (2014) brought this element explicitly to the forefront by stating that:

"The application of such holistic considerations is very challenging, but progress can nevertheless be made through focusing on certain aspects of sustainability, such as reducing operating costs and reducing sound emissions. Tunnel ventilation provides a significant opportunity for sustainability improvements, particularly for long tunnels which can absorb significant amounts of power." ([44], p. 15)

Moreover, an integrated project management approach aimed at including sustainability seems missing. It seems evident, academic as well as practical viewpoints, that tunnel projects and its management need a more systematic approach to integrate sustainability and to make sustainability more explicit. The literature hinted in several directions. First, the term sustainability needs to 
overcome instinctive and implicit adoption of bottom-up initiatives, and needs to be clarified for its intended use in a project. Second, sustainability needs to be defined for tunnels and a sustainability assessment tool specific for tunnel projects, aimed at guiding its project management, could be helpful. Third, sustainability is all about working out the details and the clearest path to the integration of sustainability into the project is through starting to implement those aspects that made a difference or had an impact. This study seeks to uncover the starting position of practitioners at the commencing stage of a project in terms of sustainability focus by systematically surveying their perceptions on a sustainable tunnel and elaborating on the project management consequences of these perspectives.

\section{Q-Methodology}

The Q-methodology is a mixed method. It applies factor analysis to identify patterns among people's perceptions. It seeks to understand how and why people think a certain way about a topic [20]. Hence a Q-study can identify different perspectives that enrich the understanding of the topic [20]. The Q-methodology procedure consists of 5 steps (outlined in Figure 1). It first defines the concourse and develops the key set of aspects associated with the topic (called the Q-sample). Next, it seeks to select the participants having an important exposure to the topic (P-set). After the sample has generated perceptions by the interview exercise (called Q-sorting), a factor analysis is applied. This statistical output is then used to interpret how and why the practitioners think about the topic the way they do and what 'overall' perspectives can be derived.

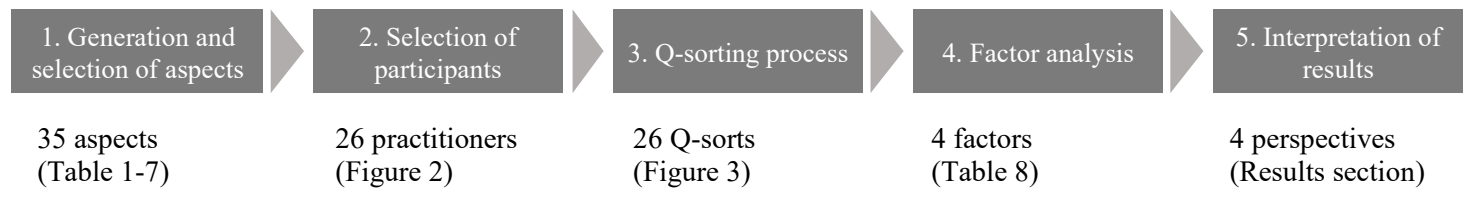

Figure 1. Q-methodology applied to elicit sustainability viewpoints.

\subsection{Developing and Selecting the Q-Sample Consisting of Sustainability Aspects}

To be able to generate the sustainability aspects that the participants need to rank, first a concourse has been defined. The concourse contains all relevant aspects and associated statements of the participants about the topic [18]. It is a collection of relevant ideas, arguments, issues and attitudes formulated in statements on a certain topic. For this paper, the topic is focused on a comprehensive set of possible sustainability aspects for tunnel projects. Different sources, including project data, expert views, literature and tools, have been used to create an extensive list of sustainability aspects. As a first step, tunnel projects mentioning to do 'something with sustainability' were given a dedicated desk search to find out which sustainability aspects were actually referred to. Secondly, experts from the fields of underground construction, geology, spatial development and energy have been interviewed about what they considered important for sustainable tunnels. Different experts were interviewed until no new aspects were mentioned during interviews. Thirdly, sustainability assessment tools and literature were explored to discover a variety of possible sustainability aspects. The selection of sustainability aspects from building assessment tools was made keeping in mind that selected aspects should possibly be applicable for tunnel projects. Also, official documents from a Dutch tunnel project associated with sustainability aspects (like Environmental Impact Assessment report and the Spatial Plan) were studied. It was reasoned that these documents from a project in its developmental stage could have included some initial sustainability aspects into its initial requirements that could cross-refer to this academic inventory of sustainability aspects. Ultimately, approximately a hundred aspects were identified with this extensive search.

The hundred initial aspects were assessed along the following criteria to ensure an attainable and relevant set within which respondents could establish their perception: 
Occurrence in sources: The number of times the aspect was mentioned in the sources, three times was selected as the minimum;

Variety of sources: Every aspect which would be adopted should at least be mentioned in two kinds of sources-for example, an expert mentioned it and it was mentioned in an assessment tool;

Level of detail: All aspects should be stated in a comparable level of detail;

Combining similar low-scoring criteria: When the definitions of aspects were very similar, these aspects were combined into one criterion.

These criteria left 35 sustainability aspects in the selection, which was recognized as an unambiguous and inclusive set that would allow practitioners to construct a perception of a sustainable tunnel. From a technical standpoint, the size falls within the required limits for applying Q-methodology. McKeown et al. [45] offer some guidance on this by advocating that a list of 20 to 80 aspects would allow for a manageable and representative proportion of statements for Q-sorting.

Tables 1-7 show the 35 sustainability aspects. These aspects are used in step 3 of the Q-methodology as the basis for the respondents to construct their perception of a sustainable tunnel. The aspects are accompanied by statements in the form of definitions, to provide respondents with the proper meaning of the aspect. The respondents were provided with an intermediate structure by grouping the 35 aspects in seven overarching themes, distinguished by the seven tables. This categorization helps to avoid confusion during the sorting process and increase the ability of participants to get familiar with the 35 aspects, without losing sight of the entire set. Finally, the categorization also provides a more straightforward interpretation for analyzing the output of the Q-sorting.

Table 1. Overview of sustainability aspects for Project Resilience.

\begin{tabular}{ccc}
\hline$\#$ & Sustainability Aspects & Definition \\
\hline 1 & Functional flexibility & The ability of the entire tunnel construction to undergo functional adaptations in \\
the future.
\end{tabular}

Table 2. Overview of sustainability aspects for Materials and Resources.

\begin{tabular}{ccc}
\hline$\#$ & Sustainability Aspects & Definition \\
\hline 7 & Use of materials and resources & Minimize the amount of materials and resources used. \\
8 & $\begin{array}{c}\text { Origin of materials and resources } \\
\text { and environmental impact }\end{array}$ & $\begin{array}{c}\text { Selection of (construction and supporting) materials with consideration for } \\
\text { minimal impact on the environment (planet). }\end{array}$ \\
9 & $\begin{array}{c}\text { Re-use and use of recycled } \\
\text { materials }\end{array}$ & Maximum re-use of components and use of recycled materials \\
and aggregates.
\end{tabular}


Table 3. Overview of sustainability aspects for Energy.

\begin{tabular}{lcc}
\hline$\#$ & Sustainability Aspects & Definition \\
\hline 11 & Energy usage & Reduction of the amount of energy required for construction and use of the \\
12 & Energy efficiency & product and services. \\
13 & Renewable energy sources & Use of (external) renewable energy sources. \\
14 & Energy production & Use of the tunnel for the production of renewable energy. (Within project scope) \\
15 & $\mathrm{CO}_{2}$ emission & Minimize $\mathrm{CO}_{2}$ emissions over entire project. (Particularly in construction phase) \\
16 & Transport & Limit negative impacts of construction-related transportation. \\
17 & Fossil fuels & Minimize use of fossil fuels. \\
\hline
\end{tabular}

Table 4. Overview of sustainability aspects for Soil and Water.

\begin{tabular}{lcc}
\hline$\#$ & Sustainability Aspects & Definition \\
\hline 18 & Water quality & Prevent pollution and minimize impact of construction on groundwater and surface \\
19 & Water usage & water quality. \\
20 & Hydrological system & Maintain regular functioning of the (ground) water system and, if necessary, take \\
21 & Use of excess soil & mitigating measures. \\
22 & Soil quality & High-quality re-use of soil released during construction. \\
23 & Value of soil & Prevent negative impact on soil quality. \\
\end{tabular}

Table 5. Overview of sustainability aspects for Health.

\begin{tabular}{lcr}
\hline$\#$ & Sustainability Aspects & Definition \\
\hline 24 & Biodiversity (Flora and Fauna) & Conservation of biodiversity and ecological connectivity, and compensation of \\
25 & potential negative impact as a result of the tunnel construction. \\
26 & Air quality & Minimize noise pollution in the area surrounding the tunnel. \\
27 & Toxic materials & Minimize emissions of air pollutants (e.g., smog, NOx). \\
& & Minimize harmful emissions from toxic materials (Volatile Organic Compounds, \\
VOC's) and resulting health hazards.
\end{tabular}

Table 6. Overview of sustainability aspects for Social.

\begin{tabular}{|c|c|c|}
\hline \# & Sustainability Aspects & Definition \\
\hline 28 & Knowledge exchange & $\begin{array}{c}\text { Exchange of information and lessons learned (relating to sustainability practices) } \\
\text { with educational and research institutes. }\end{array}$ \\
\hline 29 & Local stakeholder Involvement & $\begin{array}{l}\text { Create public support for the project and activate local expertise among future users, } \\
\text { local residents and other stakeholders. }\end{array}$ \\
\hline 30 & Human rights and fair trade & $\begin{array}{l}\text { Comply with international labor standards, respect human rights and enforce an } \\
\text { anti-corruption policy. (as per the UN Global Compact) }\end{array}$ \\
\hline 31 & Social return & $\begin{array}{l}\text { Positive contribution to employment in the region and promote employment of } \\
\text { people with poor job prospects. }\end{array}$ \\
\hline
\end{tabular}

Table 7. Overview of sustainability aspects for Business and Operations.

\begin{tabular}{|c|c|c|}
\hline$\#$ & Sustainability Aspects & Definition \\
\hline 32 & Sustainable leadership & $\begin{array}{l}\text { Personal managerial long-term commitment to the project's sustainability goals, } \\
\text { activating internal teams as well as the supply chain as a whole. }\end{array}$ \\
\hline 33 & Sustainable business operations & $\begin{array}{l}\text { A culture of sustainable business practices. (At the construction site as well as within } \\
\text { the rest of the company.) }\end{array}$ \\
\hline 34 & Life Cycle Cost & $\begin{array}{l}\text { The use of life cycle cost approach to stimulate financial considerations throughout } \\
\text { the life cycle of the tunnel. }\end{array}$ \\
\hline 35 & Value optimization & $\begin{array}{c}\text { Optimize value of the tunnel throughout the life cycle with consideration for } \\
\text { all stakeholders. }\end{array}$ \\
\hline
\end{tabular}

\subsection{Selecting Participants}

The Q-sorting process needs to be performed by a cohesive set of respondents. Here cohesion is defined as the ability of the set of respondents to offer a wide range of expected viewpoints [46]. In the context of this research, the cohesion revolves around a single tunnel project upon which a 
recognizable set of stakeholders would be reasonably expected to be involved in the developmental stages. A Dutch tunnel project was used as a frame of reference from which practitioners could be identified as stakeholders in the project. The range is categorized along with different roles in the construction process and tunnel supply chain. Following the Dutch reference project, a total of 26 different disciplines and roles were identified (see Figure 2) around the project delivery organization (PDO). The cohesion of the set can be described as a list of practitioners who worked in the construction supply chain having relevant experience with an underground construction project. Their expertise is listed in Appendix A (Table A1).

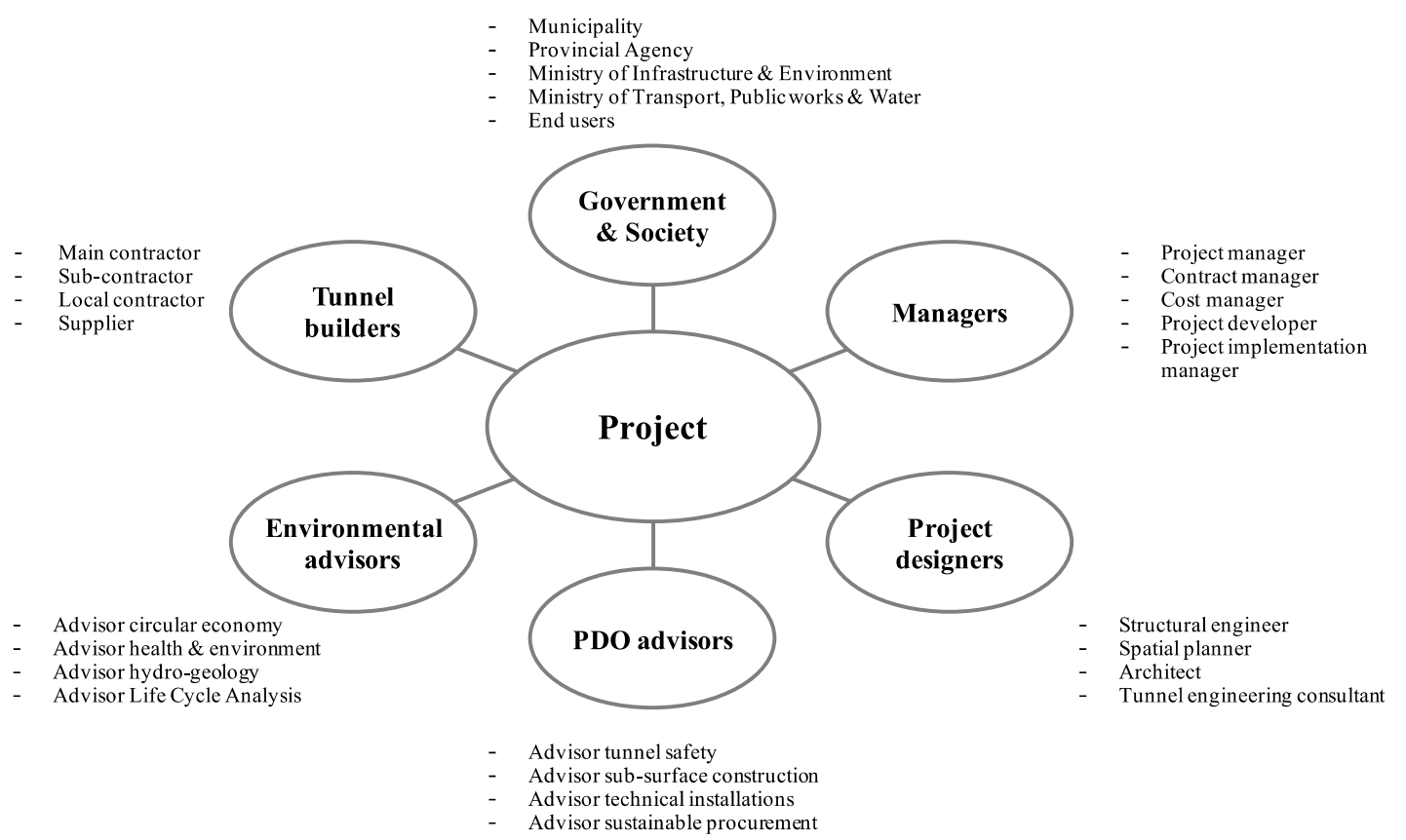

Figure 2. Selected participants and relation to tunnel projects ( $\mathrm{PDO}=$ project delivery organization).

\subsection{Q-Sorting for Eliciting the Participants' Perceptions}

The Q-methodology can be carried out either online or in person. For this study, the sorting process was assisted by a developed tool in Excel, which was distributed digitally to all the 26 respondents. In this tool, a commentary space was provided for respondents to motivate their choices. In essence, the tool guided the respondents through the formal steps of the Q-sorting without the researcher being present. During the steps, the participants were asked to rank the 35 identified sustainability aspects according to their perceived importance along one main question and answering format (see Figure 3).

The respondents were asked to move a sustainability aspect to a particular spot in the format, which according to them represented the proper level of importance of the aspect for a sustainable tunnel, i.e., not the present Dutch tunnel but a future tunnel. A 9-point scale was used with -4 as the least important, 0 as neutral and +4 for the most important. Note that the vertical location of an aspect in the sorting scheme has no meaning. Besides the ranking also some qualitative questions were asked about those aspects scoring very high and very low to unravel participants' motives in the sorting process. The outcome of the sorting process, the relative ranking or $\mathrm{Q}$ sorts, was the input for the data analysis. 


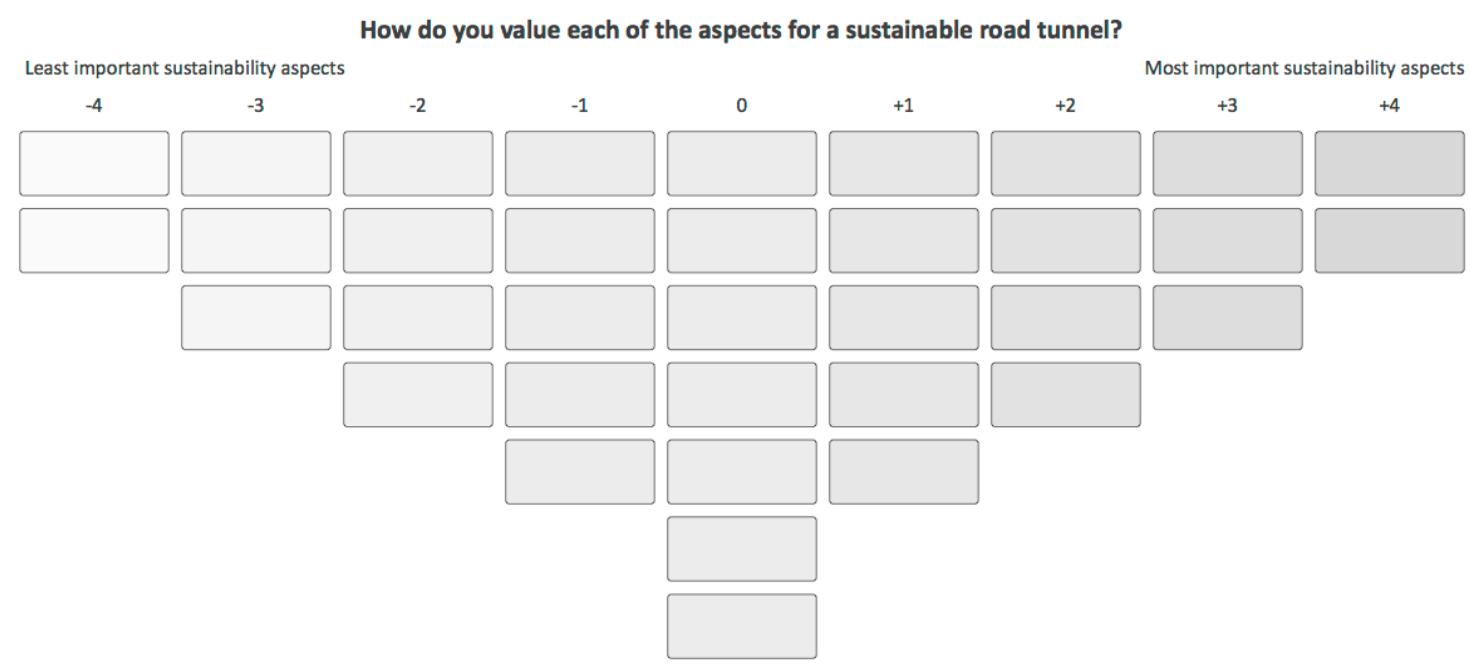

Figure 3. Sorting scheme applied.

\subsection{Factor Analysis and Interpretation on Observed Patterns of Perception}

After all 26 participants had completed the sorting process, their Q-sorts were entered into a program called PQMethod which has been specifically designed to analyze Q-sorts [47]. The program looks for inter-correlations between the Q-sorts. Factor analysis was applied to reduce the many different personal views (or Q-sorts) to a few, meaningful factors. These factors are a mathematical description of a shared perspective. The cut-off of the number of relevant factors is determined by the eigenvalues of the factors and the correlations between the factors. The factor analysis on a Q-sorted data set mathematically composes which shared perspectives exist among the sample of respondents, in this case on sustainable tunnel projects.

\section{Results}

\subsection{Identification of Perspectives}

From the data set of 26 respondents, four factors were found to meet the statistical criteria to be interpreted as shared perspectives for this study. Table 8 summarizes the loading of the respondents on the four identified factors.

These four factors fulfilled the conditions of having an eigenvalue above 1, having at least two significant loaders (indicated grey in Table 8) to this factor and a minimum number of non-loaders. Non-loaders are respondents that did not load significantly on any of the defined perspectives. In this study, 3 of the 26 respondents were non-loaders, and one respondent loaded significantly to one of the perspectives, but did not share the perspective. This respondent did have a strong opinion about the same (distinguishing) aspects as that perspective but in the opposite way. After having identified four factors reflecting four distinct perspectives on sustainable tunnels, the next step was to create the narratives of these perspectives. The qualitative comments provided by the participants during the Q-sorting process supported the process of creating names and narratives for these perspectives. For describing these narratives, we used the Z-scores, which show how far an aspect deviates from the middle of the distribution [48], and were found to be meaningful. In this study, $\mathrm{Z}$ ranged between -4 and +4 (see distribution in Figure 3).

For interpretation of the perspectives, an aspect that within a perspective has a Z-score above +1 or below -1 is taken into account. Additionally, aspects that were scored significantly different between the perspectives were included in the analysis (the so-called distinguishing statements). This resulted in names stemming from distinctive focused themes for each of the four factors. The name, contents and underlying reasons for these perspectives are elaborated next. Figure 4 shows the most important 
and least important statements for each perspective. Next, the four perspectives are discussed in more detail. In the next section, their implications for project management are discussed.

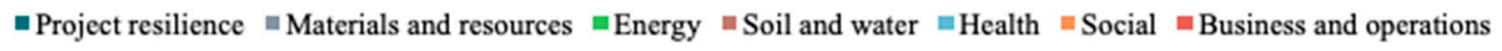

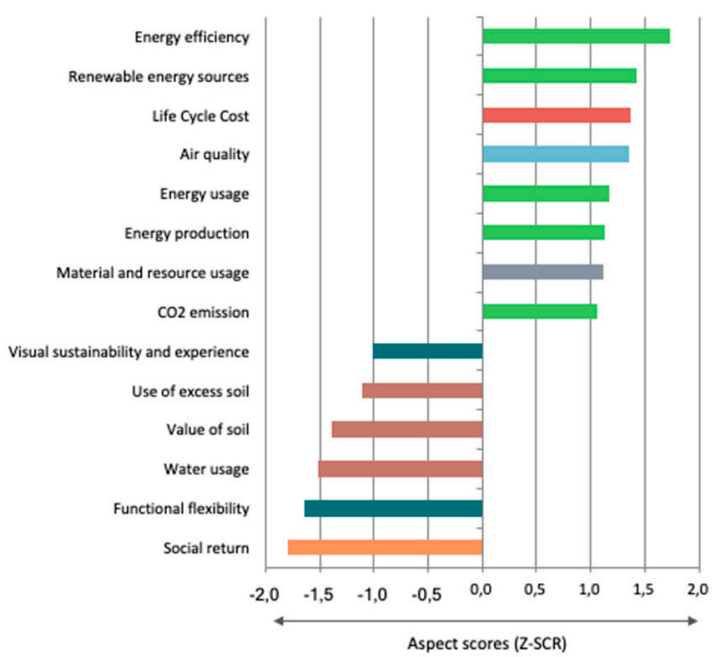

(a) Perspective 1: Energy perspective

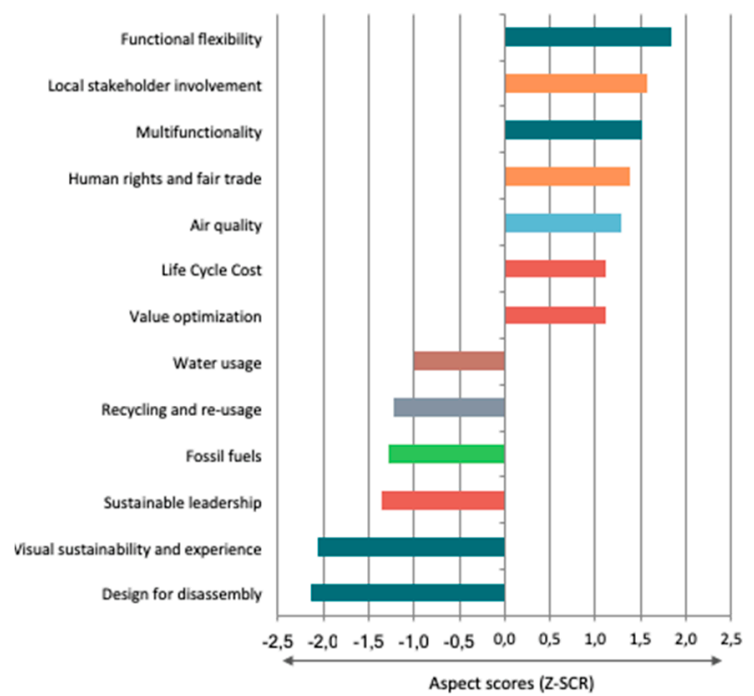

(c) Perspective 3: Social perspective

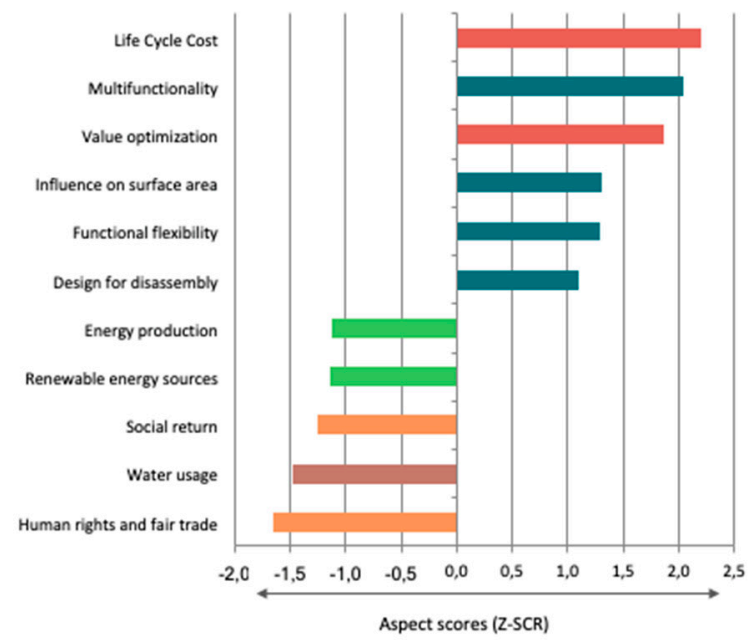

(b) Perspective 2: Resilience perspective

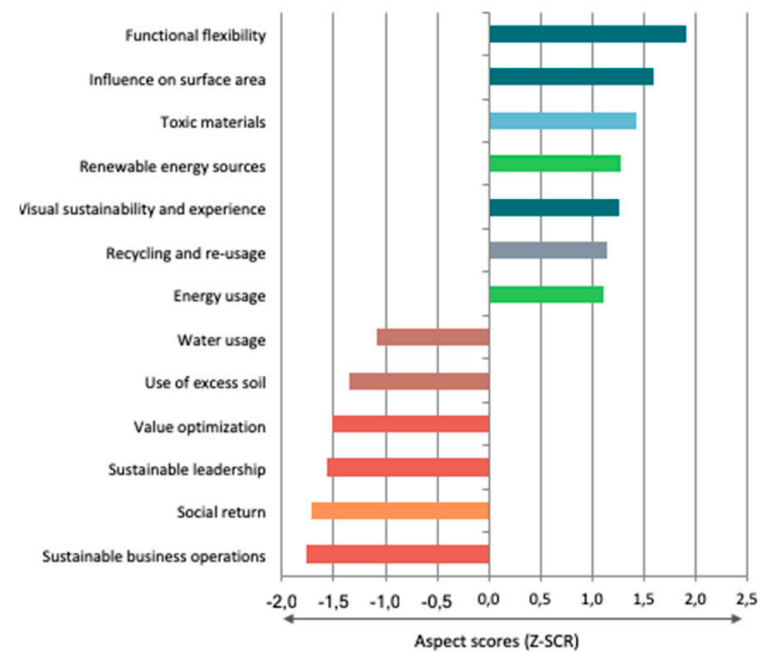

(d) Perspective 4: Transition perspective

Figure 4. Overview of the high and low scoring aspects per perspective.

\subsection{The Energy Perspective for Sustainable Tunnels}

As can be seen in Figure 4a, the aspects that are considered most important for this perspective are predominantly energy-related aspects. The people sharing this perspective have an analytical background. It is therefore not surprising that the highest valued aspects are measurable and quantifiable. They have an efficiency approach towards sustainable tunnels; according to them, energy and materials should be used as efficient as possible. Aspects such as Functional Flexibility and Visual Sustainability receive low scores since the loaders argue that these aspects would not be an efficient way to achieve a sustainable tunnel. In essence, the Energy Perspective group explicates that tunnels are sustainable when energy-use is minimized, carbon emissions are reduced and the efficiency over the project life cycle is ensured. 
Table 8. Loading of the respondents on the four factors.

\begin{tabular}{|c|c|c|c|c|}
\hline Participant \# & Perspective 1 & Perspective 2 & Perspective 3 & Perspective 4 \\
\hline 1 & 0.1202 & -0.4206 & 0.1773 & $0.5647^{*}$ \\
\hline 2 & 0.0971 & 0.0205 & 0.6364 * & 0.2170 \\
\hline 3 & 0.7620 * & -0.0375 & 0.0093 & -0.0026 \\
\hline 4 & -0.1971 & -0.2357 & 0.4452 * & -0.1168 \\
\hline 5 & -0.1773 & 0.4674 * & -0.0789 & 0.1138 \\
\hline 6 & 0.0391 & -0.0097 & 0.1522 & 0.1189 \\
\hline 7 & 0.2812 & 0.1562 & 0.3774 & $0.5315^{*}$ \\
\hline 8 & 0.4609 * & $0.5926^{*}$ & 0.1677 & -0.0281 \\
\hline 9 & 0.1437 & 0.1562 & -0.0781 & 0.1679 \\
\hline 10 & -0.2096 & 0.3648 * & 0.6410 * & -0.0235 \\
\hline 11 & 0.3169 * & $0.5587^{*}$ & -0.0129 & 0.0318 \\
\hline 12 & 0.2950 & 0.0595 & 0.0828 & 0.0189 \\
\hline 13 & 0.8044 * & 0.1602 & 0.0904 & 0.2331 \\
\hline 14 & $-0.5955^{*}$ & -0.0787 & 0.0792 & 0.2084 \\
\hline 15 & $0.5699 *$ & -0.0490 & -0.1291 & 0.1873 \\
\hline 16 & $0.3866^{*}$ & -0.2501 & $0.4262 *$ & -0.1951 \\
\hline 17 & 0.1430 & 0.7078 * & 0.0796 & 0.0010 \\
\hline 18 & 0.0456 & 0.1667 & 0.6863 * & 0.2108 \\
\hline 19 & 0.0181 & 0.0961 & -0.1552 & $0.8742 *$ \\
\hline 20 & -0.1765 & 0.6712 * & -0.0451 & 0.0604 \\
\hline 21 & 0.1348 & $0.3680 *$ & 0.2633 & $0.5567^{*}$ \\
\hline 22 & 0.4310 * & -0.3083 & 0.2030 & 0.1925 \\
\hline 23 & -0.0390 & -0.0601 & $0.8076^{*}$ & -0.1058 \\
\hline 24 & -0.0265 & 0.0358 & 0.0775 & 0.7621 * \\
\hline 25 & 0.6710 * & -0.0645 & -0.2900 & 0.3520 * \\
\hline 26 & 0.0180 & 0.7337 * & 0.1267 & 0.0460 \\
\hline
\end{tabular}

${ }^{*}$ Indicates loading at 0.05 significance level; grey cells determine loaded perspective.

\subsection{The Resilience Perspective for Sustainable Tunnels}

Another clear focus was found where participants reflected the importance of resilience and the business-related aspects, see the second perspective in Figure 4. In essence, this perspective explicates that tunnels are more sustainable when functionality and value over the project life cycle are optimized, like in terms of costs. In contrast to the Energy perspective, they do not have an efficiency but an effective approach towards sustainable tunnels. They value Functional Flexibility, Multifunctionality and Value Optimization, not because they think that is the fastest route to a sustainable tunnel but because they argue that with this way the structure's functionality and use will be optimized over the total life span of the project. For example, by relating costs to its continued service over the tunnels' life cycle. Furthermore, Multifunctionality is considered a technical and smart optimization of multiple functions. This perspective is shared by people having predominantly a (civil) engineering background. That could explain why they consider optimization issues as technical challenges, which can be used to maximize functionality over the total project life span.

\subsection{The Social Perspective for Sustainable Tunnels}

A third clear focus was found where participants chose social aspects (see Figure 4c). In essence, the participants sharing the social perspective argue that tunnels are more sustainable when local stakeholders and the direct project environment are considered during the project. The people sharing this perspective consider it as very important that (local) stakeholders are involved in the process because, according to them, this will lead to less hindrance, which will make the construction project more sustainable. Also, a focus on air quality is considered important, because of its effect on the local project environment. In comparison to the other perspectives and in comparison to the planet and profit aspects, this group scores highest on the people aspects. This could be explained by the fact that the people sharing this perspective mostly are (project) managers. In essence, they say: 
A sustainable tunnel is a tunnel that has been constructed in close cooperation and dialogue with the local environment. They also value Functional Flexibility because this way the people in the environment can use the structure for more than just one functionality.

\subsection{Transition Perspective for Sustainable Tunnels}

As the fourth perspective in Figure 4d shows, a final perspective revolves around the transition that is needed for sustainability to actually happen, in which the project resilience aspects are dominant. The aspects that this perspective values highly are pointed towards the future effect of the project on the environment. According to this perspective, tunnels are more sustainable when the harmful effects on people and the planet now and in the long-term are prevented. None of the participants sharing this perspective has a technical background. It is remarkable that they value Visual Sustainability and Experience. According to this perspective, when sustainability aspects are applied well it will be shown in the look and feel of the project. This perspective suggests that it would be valuable to involve end-users and ask them for their (future) needs to stay resilient. According to this group of people, sustainable development requires an entirely new approach in which profit aspects are not important. According to them, to achieve a sustainable tunnel, a transition is needed, particularly the circular economy is mentioned, and they say sustainability is about rethinking and redesigning in many ways.

\subsection{Comparing the Perspectives and Implications}

In Table 9 the different perspectives are summarized and the different aspects they value are presented.

Table 9. Summary of aspect scores per perspective.

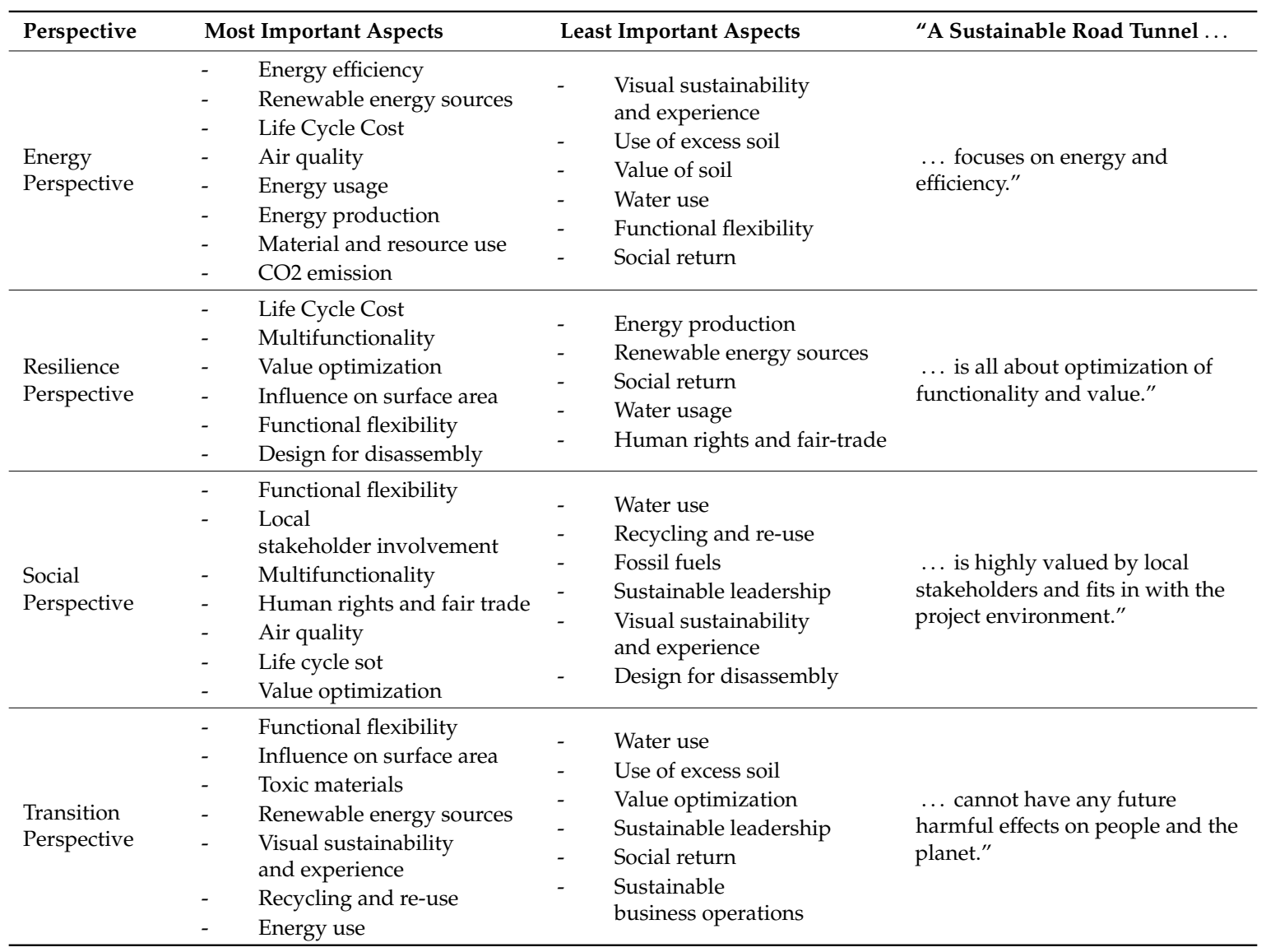

It appears that oftentimes participants with a similar background share a similar perspective. For example, (civil) engineers value flexibility and consider value optimization an interesting challenge and see Multifunctionality as a technical optimization of smart solutions. (Environmental) managers 
take the direct environment into account and the transition perspective is mostly shared by people with a bit more experience in sustainability, mostly without a technical background, and they consider sustainability not as a technical challenge but as a new perspective, a new way of thinking. This indicates that there is no such thing as 'the' sustainable tunnel, but it depends on earlier experience, expertise, background and personal view.

It could be assumed that if a person with a certain perspective could decide on what sustainability aspects to take into account in a tunnel project, and how to adjust the project management to make that happen, that this person would choose the aspects that are most important according to her or his view. As a consequence, the sustainability vision for that project would be really subjective. Following this line of reasoning, if a team consisting of different people sharing different perspectives would be given the assignment to create a sustainability vision including specific sustainability aspects, it is likely that conflicts will arise since there are no two perspectives sharing similar high scoring aspects.

Table 10 presents aspects all perspectives agreed upon. The values indicate the importance, zero implies neutral, -4 implies the least important and +4 implies the most important. There is not a single aspect highly valued by all four perspectives. At best agreement is found on aspects with a neutral or very low score.

Table 10. Consensus aspects.

\begin{tabular}{ccccc}
\hline Aspect & $\begin{array}{c}\text { Energy } \\
\text { Perspective }\end{array}$ & $\begin{array}{c}\text { Resilience } \\
\text { Perspective }\end{array}$ & $\begin{array}{c}\text { Social } \\
\text { Perspective }\end{array}$ & $\begin{array}{c}\text { Transition } \\
\text { Perspective }\end{array}$ \\
\hline Transport & 0 & 0 & 0 & -1 \\
Water usage & -3 & -4 & -2 & -2 \\
Construction Waste & 0 & 1 & 0 & 2 \\
Noise & 1 & 0 & 0 & 2 \\
\hline
\end{tabular}

Also, aspects that the perspectives mostly disagree upon (Table 11), show that different perspectives have very different opinions. Again, a score of -4 indicates this aspect is least important, a score of 0 is neutral and a score of +4 indicates that the aspect is valued as most important in that perspective.

Table 11. Disagreed aspects.

\begin{tabular}{ccccc}
\hline Aspect & $\begin{array}{c}\text { Energy } \\
\text { Perspective }\end{array}$ & $\begin{array}{c}\text { Resilience } \\
\text { Perspective }\end{array}$ & $\begin{array}{c}\text { Social } \\
\text { Perspective }\end{array}$ & $\begin{array}{c}\text { Transition } \\
\text { Perspective }\end{array}$ \\
\hline Functional flexibility & -4 & 3 & 4 & 4 \\
Value optimization & -2 & 3 & 2 & -3 \\
Visual sustainability and & -2 & 0 & -4 & 3 \\
experience & 3 & 4 & 2 & -2 \\
Life Cycle Cost & -1 & 2 & -4 & -1 \\
Design for disassembly & & & \\
\hline
\end{tabular}

Thus, the consensus and disagreement aspects, as an outcome of the program PQ method, show the differences and similarities between factors (perspectives). This way the Q-methodology provides insights for dealing with such conflicting perspectives as it makes it clearer and concrete what the agreement and disagreement aspects are. This was also experienced in this case. During the process of selecting criteria to specify sustainability for the procurement phase, it became clear that different people involved valued different aspects. Before this research was done, it was not clear why certain people were always disagreeing discussing sustainability issues. After the results of this research were shown, it was evident why they could not agree on certain issues because their hidden perspective was revealed and in discussions, specific aspects and sustainability themes could be discussed. Also, with the help of this study, people could place themselves in someone else's position (or perception) to experience their view and understand why they value certain sustainability aspects. Only after this awareness, conscious decisions can be made on specific project management choices, like the process 
of stakeholder engagement, the process of budget estimation, opportunity framing or the use of life cycle costing or not. Such project management choices could be subject to future investigations.

\section{Discussion}

It seems that the importance and interpretation of sustainability within a project highly depends on the perspective of the responsible person, mostly the client and/or project manager. As Duarte [10] stated: "It cannot be overstated that the role of the Client is fundamental to a sustainable project." And "Changing the mindset of stakeholders is a key challenge in progressions towards sustainable design and needs to be addressed at the earliest stage possible, starting with the Client and progressing through to the contractors." Clients here can be governments at different levels: (inter)national, regional and local. This research confirms that the mindset and perspective towards sustainability are crucial for how sustainability will be translated and integrated into a project and its management.

However, it is questionable if it is still acceptable that the sustainability vision for a project depends so heavily on one person's perspective. If the climate goals for 2030 and 2050 are to be achieved, the sustainability of a tunnel project cannot only depend on the motivation and perspectives of the people involved in the project. Since the sustainability challenge gets more urgent and comprehensive and the sustainability goals are getting more ambitious and concrete (Paris COP21), it seems that if and how sustainability is integrated into such a major project should no longer be optional nor coincidental.

A two-way path seems the right approach. On the one hand, some general requirements will be necessary to consistently achieve national and international sustainability goals. On the other hand, some local and project-specific sustainability criteria should be developed. "As communities are unique, the primary objectives of one community relative to sustainable development may be very different from those of another." [49]. As this research showed, sustainability may be defined differently by different persons. These definitions and priorities may even change over time [49]. However, Fischer and Amekuszi [49] also argue "As with sustainable development or economic development, variance among contextually specific operational definitions should not discourage the use of an overarching conceptual definition for Quality of Life." Thus, although some differences for a specific project (environment) need to be accepted, also an overarching concept is necessary. Therefore it is argued that an overarching and general definition with correlating criteria for sustainable tunnels should be developed as a baseline for integrating sustainability into tunnel projects. Besides, every project should develop project-specific criteria for the specific tunnel situation based on the project environment and the people involved.

The outcomes of this research, based on a Dutch context, can, on the one hand, be used as a starting point to develop such a general framework or assessment tool with sustainability criteria for tunnel projects. On the other hand, this research showed that the Q-methodology can be successfully applied in tunnel projects and it can be used to support the development of a sustainability vision and to identify project-specific sustainability aspects.

\section{Conclusions}

The main research question that this paper addresses is: What kind of perspectives on sustainability may exist with regards to tunnels and how can these help to integrate sustainability into the project?

Based on the data gathered from representatives of the tunnel supply chain, four clear perspectives on sustainable tunnels were identified, captured as the energy, resilient, social and transition perspectives. These perspectives are recognizable by a focal point of attention that is based on the preferred aspects of the participants sharing that perspective. For example, the energy view can be regarded as showing a preference for a type of consumption source that is regarded as sustainable, whereas the transition perspective really expresses the challenge of the transition needed to arrive at sustainable tunnels. Being aware of these perspectives allows the adaptation of the specific project management approach, e.g., in terms of focusing on stakeholder engagement or putting the effort into life cycle cost. 
It can be concluded that a cognitive elicitation method such as the Q-methodology can generate several benefits at the forefront of a project. First, when participants are forced to clarify their opinion towards a vague and all-encompassing term, like sustainability, they are forced to make choices and this way they show an ability to determine a coherent view that is also independently shared by peers. Second, the results of the total study show that different perspectives do exist; it shows that there is no such thing as 'the sustainable tunnel'. Most people have something different in mind when talking about a sustainable tunnel. However, and this is the third point, it does show that there are some common perspectives and that there are similarities and differences between these different perspectives. Some aspects are valued by all participants; other aspects are suitable for discussion. This could help at the forefront of a project to find commonalities as a starting point and concrete aspects for starting the discussion. Insights in the different perspectives can help to understand each other and aid collaboration to arrive at a shared perspective or sustainability goal for a tunnel project.

The contribution of this paper to the current scientific debate includes the definition of four common sustainability perspectives that illustrate a variety of viewpoints on this very important theme. This study supports a two-way approach where an overarching vision on sustainability seems required next to a more operational, project-specific approach in which project management activities are adjusted to the chosen sustainability focus.

\section{Limitations and Further Research}

To arrive at the perspectives, first, a framework with sustainability aspects was developed as input (Q-sample) for the Q-methodology. To develop this framework, the researchers have reviewed many sources with the purpose to collect a broad inventory of possible sustainability aspects. It is however important to note that these aspects could not be studied in depth. This process has been sufficient for purposes of the perspective elicitation, but in-depth research is required when wanting to use this framework of sustainability aspects separately. Nevertheless, the current framework could be good inspiration for further development of such a framework with sustainability aspects or an assessment tool for tunnel projects. Further research could revolve around the development and use of decision support systems like multi-criteria decision analysis, see for example [50], and its link to the Q-methodology applied in our research.

The elicited perspectives have been particularly established by the coherence of the participants that were involved in the case study project. Although their view for a generic sustainable tunnel was asked (future, not present), the extent to which the reference project may have played a role in the creation of these particular perspectives cannot be fully controlled. Nonetheless, the identified perspectives seem generically applicable to sustainability approaches, even in other (related) sectors. For example, in urban development, similar approaches have been recognized. In [51] these perspectives were reflected in different city categories that they showed have entered the policy discourse such as the low carbon city (energy perspective) and eco or green cities (resilience perspective). The social perspective is presented in this sector by the fair-trade town movement [52]. And, lastly, the transition perspective shows similarities with the circular cities' movement as according to Prendeville, Cherim and Bocken [53], many cities are turning to the 'circular economy' concept that was mentioned by participants sharing the transition perspective as well. Subsequent research could further operationalize project management practices in order to align with certain sustainability perspectives.

A new research angle could be whether these perspectives are indeed recognizable as such in other related industries and sectors. And future work could be pursued to test the practical applicability of the perspectives. According to Cuppen et al. [54] the Q-methodology can also be used for measuring the change in perspectives. This could be interesting follow-up research, to investigate if and how the perspectives towards sustainable tunnels change within the industry.

Author Contributions: This paper is a further development of the following master thesis [55], Tunnel Visions on Sustainability: Sustainability aspects and its selection process for road tunnel construction projects. Delft-Delft University of Technology. After this report, the research has been continued from the AMS Institute in Amsterdam 
in collaboration with Delft University of Technology. Investigation, D.G.; conceptualization, all; methodology, formal analysis and writing, D.G., M.B.-R., D.S.; supervision M.H. All authors have read and agreed to the published version of the manuscript.

Funding: This research received no external funding.

Acknowledgments: The authors are grateful for the inputs provided by the respondents.

Conflicts of Interest: The authors declare no conflict of interest.

\section{Appendix A Expertise of the Respondents}

Table A1. List of expertise in the respondent's group (ordered alphabetically).

\begin{tabular}{|c|}
\hline Circular economy \\
\hline Complex infrastructural and soil projects \\
\hline Contract manager Roads and traffic \\
\hline Coordinator road constructions \\
\hline Electrical and tunnel technical installations \\
\hline Environmental footprints and Life Cycle Analysis \\
\hline Financial expert infrastructural projects \\
\hline Geoengineering \\
\hline Innovation and market \\
\hline Logistics and sustainability \\
\hline Nature and Environment \\
\hline Project Coordination and civil engineering \\
\hline Project director \\
\hline Representing interest of local companies \\
\hline Spatial planning \\
\hline Stakeholder management \\
\hline Structural safety \\
\hline Subsurface construction \\
\hline Sustainability advisor \\
\hline Systems Engineering and Asset Management \\
\hline Tunnel engineering \\
\hline Tunnel safety and installation technology \\
\hline Tunneling \\
\hline Tunnels engineering \\
\hline Underground architecture \\
\hline Water and soil quality \\
\hline
\end{tabular}

\section{References}

1. Akadiri, P.O.; Chinyio, E.A.; Olomolaiiye, P.O. Design of a sustainable building: Conceptual framework for implementing sustainability in the building sector. Buildings 2012, 2, 126-152. [CrossRef]

2. Daneshpour, H. Integrating sustainability into management of project. Int. J. Environ. Sci. Dev. 2015, 6, 321. [CrossRef]

3. Martens, M.L.; Carvalho, M.M. The challenge of introducing sustainability into project management function: Multiple-case studies. J. Clean. Prod. 2016, 117, 29-40. [CrossRef]

4. Tamak, R. Project Management for Sustainability; Delft University of Technology: Delft, The Netherlands, 2017. 
5. Silvius, G.; Schipper, R.; Planko, J. Sustainability in Project Management; Routledge: London, UK, 2012.

6. Kivilä, J.; Martinsuo, M.; Vuorinen, L. Sustainable project management through project control in infrastructure projects. Int. J. Proj. Manag. 2017, 35, 1167-1183. [CrossRef]

7. Fernández-Sánchez, G.; Rodríguez-López, F. A methodology to identify sustainability indicators in construction project management-Application to infrastructure projects in Spain. Ecol. Indic. 2010, 10, 1193-1201. [CrossRef]

8. Willetts, R.; Burdon, J.; Glass, J.; Frost, M. Environmental and sustainability impact assessment of infrastructure in the United Kingdom. Transp. Res. Rec. 2010, 2158, 143-150. [CrossRef]

9. Hafner, A.; Vollmann, G.; Thewes, M. Urban infrastructure in connection to sustainability issues. In Life-Cycle of Engineering Systems: Emphasis on Sustainable Civil Infrastructure, Proceedings of the Fifth International Symposium on Life-Cycle Civil Engineering (IALCCE 2016), Delft, The Netherlands, 16-19 October 2016; CRC Press: Boca Raton, FL, USA, 2016; p. 440.

10. Duarte, P.; Thomas, A.; Cooke, M. Sustainability and the tunnelling industry. In Proceedings of the UNDER CITY Colloquium on Using Underground Space in Urban Areas in South-East Europe, Dubrovnik, Croatia, 12-14 April 2012.

11. PIARC Technical Committee 3.3 Road Tunnel Operation. Road Tunnel Operations: First Steps towards a Sustainable Approach (Technical Report 2017RO2EN); PIARC Technical Committee 3.3 Road Tunnel Operation: Paris, France, 2017.

12. Duarte, P.; MacDonals, M.; Cooke, M.; Thomas, A. Sustainability and the Tunneling Industry. Available online: https://www.tunneltalk.com/TunnelTECH-Dec2013-Sustainability-and-the-tunnelling-industry.php (accessed on 24 October 2018).

13. Chatham House. Making Concrete Change: Innovation in Low-carbon Cement and Concrete; Chatham House: London, UK, 2018.

14. Clinning, G.; Marnewick, C. Incorporating sustainability into IT project management. S. Afr. Comput. J. 2017, 29, 1-26. [CrossRef]

15. Marcelino-Sádaba, S.; González-Jaen, L.; Pérez-Ezcurdia, A. Using project management as a way to sustainability. From a comprehensive review to a framework definition. J. Clean. Prod. 2015, 99. [CrossRef]

16. Anderson, R. Ray Anderson on Project Managers and Sustainability. Available online: https://www.youtube. com/watch?v=bnUbuginMGE (accessed on 24 October 2018).

17. Liu, X.; Schraven, D.; de Bruijne, M.; de Jong, M.; Hertogh, M. Navigating Transitions for Sustainable Infrastructures-The Case of a New High-Speed Railway Station in Jingmen, China. Sustainability 2019, 11, 4197. [CrossRef]

18. Van Exel, J.; De Graaf, G. Q methodology: A sneak preview. Retrieved Jan. 2005, 24, 2009.

19. Barry, J.; Proops, J. Seeking sustainability discourses with Q methodology. Ecol. Econ. 1999, 28, 337-345. [CrossRef]

20. Brown, M. Illuminating Patterns of Perception: An Overview of Q Methodology (No. CMU/SEI-2004-TN-026); Carnegie-Mellon Univ Pittsburgh: Pittsburgh, PA, USA, 2004.

21. Silvius, A.J.G. Sustainability in project management. In Projects and People-Mastering Success; NAP-Process Industry Network: Nijkerk, The Netherlands, 2018.

22. Silvius, G.; Schipper, R. A maturity model for integrating sustainability in projects and project management. In Proceedings of the 24th World Congress of the International Project Management Association, Istanbul, Turkey, 1-3 November 2010.

23. Silvius, G.; Schipper, R. Developing a Maturity Model for Assessing Sustainable Project Management. J. Mod. Proj. Manag. 2015, 3, 17-27. [CrossRef]

24. GPM Global. P5 Standard for Sustainability in Project Management Version 1; GPM Global: Detroit, MI, USA, 2014.

25. Szabó, L. Sustainability, Creativity and Innovation in Project Management-Model Development for Assessing Organizational Performance Through Projects. Vezetéstudomány 2016, 47, 3-18.

26. Tam, C.K.G. Project Sustainability Impact Assessment. In Managerial Strategies and Green Solutions for Project Sustainability; IGI Global: Hershey, PA, USA, 2017. [CrossRef]

27. Griffiths, K.A.; Boyle, C.; Henning, T.F. Comparative Assessment of Infrastructure Sustainability Rating Tools (No. 17-01265); Transportation Research Board: Washington, DC, USA, 2017. 
28. Griffiths, K.; Boyle, C.; Henning, T.F. Beyond the Certification Badge-How Infrastructure Sustainability Rating Tools Impact on Individual, Organizational, and Industry Practice. Sustainability 2018, 10, 1038. [CrossRef]

29. Briassoulis, H. Sustainable development and its indicators: Through a (planner's) glass darkly. J. Environ. Plan. Manag. 2001, 44, 409-427. [CrossRef]

30. Silvius, A.J.; Schipper, R.P. Sustainability in project management: A literature review and impact analysis. Soc. Bus. 2014, 4, 63-96. [CrossRef]

31. Wang, S.H.M.; Williams, P.; Shi, J.; Yang, H. From Green to Sustainability-Trends in the Assessment Methods of Green Buildings. Front. Eng. Manag. 2015, 2, 114-121. [CrossRef]

32. UK Green Building Council. Delivering Low Carbon Infrastructure. Available online: https://www.ukgbc. org/wp-content/uploads/2017/09/Delivering-Low-Carbon-Infrastructure.pdf (accessed on 8 October 2018).

33. Huang, L.; Bohne, R.A.; Bruland, A.; Jakobsen, P.D.; Lohne, J. Life cycle assessment of Norwegian road tunnel. Int. J. Life Cycle Assess. 2015, 20, 174-184. [CrossRef]

34. Hlad, C. Sustainable Design Strategies for Tunneling Projects. Available online: https://ucononline.com/2011/ 07/sustainable-design-strategies-for-tunneling-projects/ (accessed on 9 October 2018).

35. Gil-Martin, L.M.; Peña-García, A.; Hernández-Montes, E.; Espín-Estrella, A. Tension structures: A way towards sustainable lighting in road tunnels. Tunn. Undergr. Space Technol. 2011, 26, 223-227. [CrossRef]

36. Gil-Martin, L.M.; Peña-García, A.; Jiménez, A.; Hernández-Montes, E. Study of light-pipes for the use of sunlight in road tunnels: From a scale model to real tunnels. Tunn. Undergr. Space Technol. 2014, 41, 82-87. [CrossRef]

37. Salata, F.; Golasi, I.; Bovenzi, S.; Vollaro ED, L.; Pagliaro, F.; Cellucci, L.; Vollaro, A.D.L. Energy optimization of road tunnel lighting systems. Sustainability 2015, 7, 9664-9680. [CrossRef]

38. Tarada. Is Tunnel Ventilation Sustainable? Available online: https://mosen.global/wp-content/uploads/2011/ 01/Is-Tunnel-Ventilation-Sustainable.pdf (accessed on 10 October 2018).

39. Zhang, Z.; Lei, Q.; Xue, Q. Ecological Tunnel for the 21st Century: A New Conception and Methodology. J. Transp. Technol. 2011, 1, 54. [CrossRef]

40. Pena-Garcia, A.; Gil-Martin, L.M.; Hernández-Montes, E. Use of sunlight in road tunnels: An approach to the improvement of light-pipes' efficacy through heliostats. Tunn. Undergr. Space Technol. 2016, 60, 135-140. [CrossRef]

41. Namin, F.S.; Ghafari, H.; Dianati, A. New model for environmental impact assessment of tunneling projects. J. Environ. Prot. 2014, 5, 530. [CrossRef]

42. Ritter, S.; Einstein, H.H.; Galler, R. Planning the handling of tunnel excavation material-A process of decision making under uncertainty. Tunn. Undergr. Space Technol. 2013, 33, 193-201. [CrossRef]

43. Moretti, L.; Cantisani, G.; Di Mascio, P. Management of road tunnels: Construction, maintenance and lighting costs. Tunn. Undergr. Space Technol. 2016, 51, 84-89. [CrossRef]

44. Tarada. Sustainable Tunnel Ventilation. Available online: https://mosen.global/wp-content/uploads/2014/12/ Sustainable-Tunnel-Ventilation.pdf (accessed on 10 October 2018).

45. McKeown, M.; Hinks, M.; Stowell-Smith, M.; Mercer, D.; Forster, J. Q methodology, risk training and quality management. Int. J. Health Care Qual. Assur. 1999, 12, 254-266. [CrossRef]

46. Watts, S.; Stenner, P. Q-methodology. Handbook of Qualitative Research in Psychology; SAGE: London, UK, 2008.

47. Schmolck, P. PQMethod Download Page for Windows Users. Available online: http://schmolck.org/qmethod/ downpqwin.htm (accessed on 18 October 2018).

48. Webler, T.; Danielson, S.; Tuler, S. Using Q Method to Reveal Social Perspectives in Environmental Research; Social and Environmental Research Institute: Greenfield, MA, USA, 2009; Volume 54, pp. 1-45.

49. Fischer, J.M.; Amekudzi, A. Quality of life, sustainable civil infrastructure, and sustainable development: Strategically expanding choice. J. Urban Plan. Dev. 2011, 137, 39-48. [CrossRef]

50. Guarini, M.R.; Battisti, F.; Chiovitti, A. A methodology for the selection of multi-criteria decision analysis methods in real estate and land management processes. Sustainability 2018, 10, 507. [CrossRef]

51. De Jong, M.; Joss, S.; Schraven, D.; Zhan, C.; Weijnen, M. Sustainable-smart-resilient-low carbon-eco-knowledge cities; making sense of a multitude of concepts promoting sustainable urbanization. J. Clean. Prod. 2015, 109, 25-38. [CrossRef]

52. Lyon, S. Fair Trade Towns USA: Growing the market within a diverse economy. J. Political Ecol. 2014, 21, 145-160. [CrossRef] 
53. Prendeville, S.; Cherim, E.; Bocken, N. Circular cities: Mapping six cities in transition. Environ. Innov. Soc. Transit. 2018, 26, 171-194. [CrossRef]

54. Cuppen, E.; Breukers, S.; Hisschemöller, M.; Bergsma, E. Q methodology to select participants for a stakeholder dialogue on energy options from biomass in the Netherlands. Ecol. Econ. 2010, 69, 579-591. [CrossRef]

55. Gijzel, D.J. Tunnel Visions on Sustainability: Sustainability Aspects and Its Selection Process for Road Tunnel Construction Projects; Delft University of Technology: Delft, The Netherlands, 2014.

(C) 2019 by the authors. Licensee MDPI, Basel, Switzerland. This article is an open access article distributed under the terms and conditions of the Creative Commons Attribution (CC BY) license (http://creativecommons.org/licenses/by/4.0/). 